\title{
Can the Canadian Syncope Risk Score (CSRS) help to risk stratify emergency department patients presenting with syncope without an evident serious cause?
}

\author{
Kelsey M. Ragan ${ }^{1,2} \cdot$ Katie Y. Lin ${ }^{1}$ \\ Received: 23 August 2020 / Accepted: 23 September 2020 / Published online: 10 December 2020 \\ (c) Canadian Association of Emergency Physicians (CAEP)/ Association Canadienne de Médecine d'Urgence (ACMU) 2020
}

Keywords Emergency medicine $\cdot$ Syncope $\cdot$ Clinical decision rules $\cdot$ Risk score

Full Citation: Thiruganasambandamoorthy V, Sivilotti MLA, Le Sage N, Yan JW, Huang P, Hegdekar M, et al. Multicenter Emergency Department Validation of the Canadian Syncope Risk Score. JAMA Intern Med. 2020; 180(5):737-744. https://doi.org/10.1001/jamaintern med.2020.0288

Link: https://jamanetwork.com/journals/jamainternalmed icine/article-abstract/2763181

Article Type: Prospective multicentre cohort study

Ratings: Methods 4/5, Usefulness 4/5

\section{Introduction}

\section{Background}

Syncope is a common and often benign presentation to emergency departments (EDs); however, syncope risk stratification remains a challenge for emergency physicians.

\section{Objectives}

The Canadian Syncope Risk Score (CSRS) validation study aims to determine the CSRS's ability to predict 30-day

Kelsey M. Ragan

kelsey.ragan@ucalgary.ca

1 Department of Emergency Medicine, University of Calgary, Calgary, AB, Canada

2 Foothills Medical Centre, Main Building 11th Flr-C1150 block, 1403 29th St NW, Calgary, AB T2N 2T9, Canada serious adverse events in patients presenting to ED with syncope.

\section{Methods}

\section{Design}

Prospective, multicentre cohort study.

\section{Setting}

Nine tertiary care academic EDs in Ontario, Quebec, British Columbia and Manitoba.

\section{Inclusion}

Patients $\geq 16$ years presenting to the ED within $24 \mathrm{~h}$ of a syncopal event in which no serious underlying condition was evident.

\section{Exclusion}

Prolonged loss of consciousness ( $>5 \mathrm{~min}$ ), altered mental status, witnessed seizure, head trauma, hospitalization required for traumatic injuries, unable to obtain history or consent, and obvious cause identified on index visit.

\section{Outcomes}

Primary outcome was 30-day serious adverse events including: any arrhythmia, need for a pacemaker or cardioversion, structural heart disease, myocardial infarction, aortic dissection, pulmonary embolism, pulmonary hypertension, subarachnoid hemorrhage or death from any cause. 


\section{Main results}

The mean observed probability of serious outcomes in the validation cohort was $3.65 \%$ (95\% CI 3.09-4.28\%). A total of $160(3.9 \%)$ of patients were excluded as serious conditions were identified during initial ED assessment. Of the $N=3819$ patients included in the analysis, 139 (3.6\%; 95\% CI 3.1-4.3\%) patients experienced 30-day serious outcomes.

In the low-risk groups, $0.3 \%$ of very low risk and $0.7 \%$ of low-risk patients experienced any serious 30-day outcome with no ventricular arrhythmias or deaths observed. In the highest risk group, $51.3 \%$ of patients experienced any serious outcome with 7 deaths and 33 arrhythmias observed.

At a threshold score of -1 , the CSRS performed with a sensitivity of $97.8 \%$ (95\% CI 93.8-99.6\%) and a specificity of $44.3 \%$ (95\% CI 42.7-45.9\%). The AUC of the model was 0.91 (95\% CI 0.88-0.93).

\section{Appraisal}

\section{Strengths}

- Large, prospective cohort with consecutive patient enrolment

- Multiple recruitment sites across Canada

- Excluded patients with evident serious pathology (and, therefore, clear disposition plan)

- Sensitivity analysis done for both missing troponin data and patients lost to follow-up

- Reasonable follow-up period (30 days)

- Assumed death from any cause related to arrhythmia (conservative estimate of risk)

- Methodical and thorough multi-step follow-up (hospital visits, telephone interview and administrative data)

- Low number $(n=152,3.7 \%)$ of patients lost to follow-up

- Adherent to STROBE reporting guidelines

\section{Limitations}

- Missing troponin value for $41 \%$ of patients

- Fewer patients in higher risk groups making the sensitivity and specificity estimates in these groups less reliable

- Score relies on clinician gestalt of cardiac versus vasovagal syncope

- Nearly $20 \%$ of eligible patients not recruited or entered in study

- No analysis of how/if admission and discharge patterns were impacted by score implementation (however, only $6.5 \%$ of the total cohort was classified as high or very high risk and, therefore, likely minimal impact on admission rate)

\section{Context}

Prior attempts to develop syncope risk prediction tools for the ED include the San Francisco Syncope Rule (SFSR) and Risk Stratification of Syncope in the Emergency Department (ROSE) rule. Both SFSR and ROSE had lower performance on validation (SFSR sensitivity $87 \%$, specificity $52 \%$; ROSE sensitivity $87.2 \%$, specificity $65.5 \%$ ), and included patients with serious pathology identified in the ED [1, 2]. A syncope risk tool is appealing for identifying patients who may benefit from admission or expedited workup. However, future research should explore how the CSRS performs compared to physician gestalt and the impact it may have on admission decisions, as similar tools have not shown benefit over clinical judgment [3].

\section{Bottom line}

The Canadian Syncope Risk Score (CSRS) was successfully validated in this large, multicentre prospective cohort study. The CSRS performed well to identify patients presenting with syncope who are at low risk of serious 30-day outcomes and, therefore, appropriate for ED discharge. Importantly, the rule is easy to use and does not rely on uncommonly ordered biomarkers (e.g. BNP) or unnecessary physical exams (e.g. rectal exam). Unlike previously developed syncope risk tools (SFSR, ROSE), CSRS provides a more nuanced assessment of risk categorization and is designed to be used in patients without an evident serious cause of syncope on initial exam.

\section{Compliance with ethical standards}

Conflict of interest The authors declare no conflict of interest.

\section{References}

1. Saccilotto RT, Nickel CH, Bucher HC, Steyerberg EW, Bingisser R, Koller MT. San Francisco Syncope Rule to predict short-term serious outcomes: a systematic review. CMAJ. 2011;183(15):E1116-26.

2. Reed MJ, Newby DE, Coull AJ, Prescott RJ, Jacques KG, Gray AJ. The ROSE (Risk Stratification of Syncope in the Emergency Department) Study. J Am Coll Card. 2010;55(8):713-21.

3. Constantino G, Casazza G, Reed M, Bossi I, Sun B, Del Rosso A, et al. Syncope risk stratification tools vs clinical judgement: an individual patient data meta-analysis. Am J Med. 2014;127(11):1126.e13-1126.e25. 